\title{
Controle biológico de tricostrongilídeos (Nematoda: Trichostrongyloidea) gastrintestinais de bovinos pelo fungo Monacrosporium sinense
}

\author{
[Biological control of gastrointestinal trichostrongylids (Nematoda: Trichostrongyloidea) of cattle by pellets of \\ Monacrosporium sinense] \\ J.V. Araújo, R.C.L. Assis, P.H. Alves, A.K. Campos, J.R. Gandra \\ Departamento de Veterinária - Universidade Federal de Viçosa \\ Av. P.H. Rolfs, $\mathrm{s} / \mathrm{n}$ \\ 36570-000 - Viçosa, MG
}

\begin{abstract}
RESUMO
Avaliou-se a resistência do fungo nematófago Monacrosporium sinense (isolado SF 470) em passar pelo trato gastrintestinal de bovinos e testou-se sua capacidade predatória sobre larvas infectantes de tricostrongilídeos após a passagem. Cem gramas de péletes formulados em matriz de alginato de sódio do isolado fúngico de $M$. sinense foram administrados, por via oral (VO), a dois bezerros mestiços holandês $\times$ zebu de seis meses de idade. Para o controle utilizaram-se dois outros animais, de igual padrão, aos quais foram administrados $100 \mathrm{~g}$ de péletes, $\mathrm{VO}$, livre do isolado fúngico. Amostras fecais, coletadas nos tempos de $12 \mathrm{~h}, 18 \mathrm{~h}, 24 \mathrm{~h}, 48 \mathrm{~h}, 72 \mathrm{~h}$ e $96 \mathrm{~h}$ após os tratamentos, foram acondicionadas em placas de Petri e em coproculturas a $25^{\circ} \mathrm{C}$ por 15 dias. Houve redução $(\mathrm{P}<0,05)$ no número de larvas infectantes de Cooperia spp. e Haemonchus spp. nos animais tratados em relação ao grupo-controle. A diferença ao final do experimento foi de $69,9 \%$ nas placas e $61,3 \%$ nas coproculturas. O fungo $M$. sinense demonstrou ser efetivo no controle de larvas infectantes de Cooperia spp e Haemonchus spp em condições de laboratório.
\end{abstract}

Palavras-chave: controle biológico, fungo nematófago, Monacrosporium sinense, Cooperia spp., Haemonchus spp.

\begin{abstract}
This study aimed to evaluate the viability of the predatory fungi Monacrosporium sinense (SF 470 isolate) to prey infective trichostrongylids larvae of cattle after the test of passage through the gastrointestinal tract. One hundred grams of pellets with the isolate of $\mathrm{M}$. sinense were orally administered to two sixmonth-old holstein $\times$ zebu crossbred calves. Two similar animals that orally received $100 \mathrm{~g}$ of pellets without the fungal isolate were used as control. Fecal samples collected at 12, 18, 24, 48, 72 and 96 hours after the treatments were allocated in Petri dishes and in fecal cultures and incubated for 15 days at $25^{\circ} \mathrm{C}$. There was significant reduction $(P<0.05)$ of the average number of infective larvae of Cooperia spp. and Haemonchus spp. in the animals treated with the fungus when compared to the control calves. At the end of the experiment, the differences were $69.9 \%$ in the Petri dishes and $61.3 \%$ in the fecal cultures. The fungi $\mathrm{M}$. sinense was effective in the control of infective gastrointestinal trichostrongylids larvae of cattle in laboratory conditions.
\end{abstract}

Keywords: biological control, nematophagous fungi, Monacrosporium sinense, Cooperia spp., Haemonchus spp.

Projeto financiado pela FAPEMIG e Fundação o Boticário Recebido para publicação em 30 de outubro de 2003 Recebido para publicação, após modificações, em 24 de março de 2004

E-mail: jvictor@ufv.br 


\section{INTRODUÇÃO}

O controle biológico mediante utilização de fungos nematófagos tem potencial para se tornar uma importante estratégia para controlar os nematóides gastrintestinais em bovinos. As helmintoses são responsáveis por expressivos prejuízos à pecuária, por causarem atraso no desenvolvimento animal, morte e gastos excessivos com manejo, redução da produtividade do rebanho e, conseqüentemente, aumento das perdas econômicas. $\mathrm{O}$ aparecimento de resistência aos princípios ativos antihelmínticos, a ocorrência de resíduos na carne e no leite e a ecotoxidade de alguns compostos despertaram o interesse na busca de novas práticas de controle das nematodioses gastrintestinais de bovinos.

Recentemente, os avanços ocorreram no desenvolvimento de vacinas contra parasitas de ruminantes (Meeusen, 1996), na seleção de animais geneticamente resistentes (Woolaston e Baker, 1996) e no controle biológico, particularmente pela utilização de fungos nematófagos (Araújo et al., 1998). Essa última alternativa tem sido uma das mais promissoras (Waller e Larsen, 1993).

Esses fungos são os organismos mais amplamente estudados no controle biológico e quase todos reduzem efetivamente a população de nematóides em ensaios no laboratório e nas pastagens (Waller e Larsen, 1993). As espécies de Monacrosporium têm eficácia comprovada sobre fitonematóides, nematóides de vida livre e nematóides parasitas de bovinos, caprinos e equinos (Araújo et al., 1992; Gomes et al., 1999; Castro 2000; Melo et al., 2003).

Em ensaios preliminares, Araújo (1996) e Araújo et al. $(1996 ; 1999 ; 2000 a)$ conseguiram a passagem de fungos nematófagos pelo trato gastrintestinal de bovinos e o controle significativo da contaminação das pastagens por nematóides parasitos de bovinos.

O objetivo deste trabalho foi avaliar a viabilidade do fungo Monacrosporium sinense (isolado SF 470) em predar larvas infectantes de tricostrongilídeos após a passagem através do trato gastrintestinal de bovinos.

\section{MATERIAL E MÉTODOS}

Um isolado de fungo predador da espécie $M$. sinense (SF 470) foi repicado a cada quatro meses e mantido em tubos de ensaio, contendo corn meal ágar 2\% (CMA $2 \%$ ) a $4^{\circ} \mathrm{C}$ e no escuro. Esse isolado, oriundo de solo brasileiro, foi obtido pelo método de espalhamento do solo (Duddington, 1955, modificado por Santos et al. (1991).

Para induzir a formação de micélio fúngico, discos de cultura de aproximadamente $5 \mathrm{~mm}$ de diâmetro foram transferidos para frascos de erlenmeyer de $250 \mathrm{ml}$, contendo $150 \mathrm{ml}$ de meio líquido GPY (glicose, peptona sódica e extrato de levedura), pH 6,5, sob agitação de $120 \mathrm{rpm}$, no escuro e à temperatura de $26^{\circ} \mathrm{C}$, por sete dias.

Os péletes foram confeccionados em matriz de alginato de sódio, conforme descrição de Walker e Connick (1983) e modificado por Lackey et al. (1993).

Quatro bovinos mestiços holandês $\times$ zebu, do sexo masculino, de aproximadamente seis meses de idade e naturalmente infectados, foram mantidos confinados em baias com piso de cimento. Os animais foram divididos em dois grupos (controle e tratado), com dois bezerros em cada um, escolhidos aleatoriamente. Após a contagem de ovos por grama de fezes (OPG), de acordo com o método de Gordon e Whitlock (1939), e a confirmação da infecção helmíntica, os bovinos receberam silagem de milho ad libitum e $2 \mathrm{~kg}$ de ração comercial por animal/dia, em três dias antes e durante o período experimental. Em seguida, os animais do grupocontrole receberam por via oral (VO), em dose única, 100 gramas de péletes de alginato de sódio sem o isolado fúngico. Os tratados receberam 100 gramas de péletes com isolado de $M$. sinense, na mesma formulação de alginato de sódio, por $\mathrm{VO}$, em dose única.

As amostras fecais foram coletadas diretamente do reto de cada animal às $12 \mathrm{~h}, 18 \mathrm{~h}, 24 \mathrm{~h}, 48 \mathrm{~h}$, $72 \mathrm{~h}$ e $96 \mathrm{~h}$ após a administração do isolado. Dois gramas de fezes foram removidos das amostras de cada bezerro e distribuídos em placas de Petri de $9 \mathrm{~cm}$ de diâmetro, contendo $20 \mathrm{ml}$ de agar água $2 \%$. Com as mesmas amostras foram realizadas coproculturas (20g de fezes misturadas com carvão vegetal fragmentado e umedecido). As 
larvas infectantes de nematóides (L3) foram identificadas segundo os critérios propostos por Keith (1953).

De cada tempo estabelecido foram realizadas cinco repetições de placas e cinco repetições de coprocultura, totalizando 30 amostras de $2 \mathrm{~g}$ e 30 de $20 \mathrm{~g}$ para cada animal. As placas e coproculturas foram incubadas a $25^{\circ} \mathrm{C}$ no escuro, durante 15 dias. Após esse período, realizou-se a coleta das L3 com auxílio do funil de Baermann com água a $42^{\circ} \mathrm{C}$, por seis horas, no qual as L3 foram recuperadas e quantificadas. Nas placas de Petri foram feitas leituras diárias para a pesquisa de conídios e conidióforos, característicos do isolado testado, e analisados com base na chave proposta por Liu e Zhang (1994).

Os resultados foram submetidos à análise de variância e de regressão linear.

\section{RESULTADOS E DISCUSSÃO}

Nas amostras fecais observou-se a presença de conídios do fungo $M$. sinense (SF 470) nas placas de Petri referentes a todos os tempos testados, após cinco dias de incubação. Ribeiro (2002) demonstrou a capacidade de passagem dos isolados $M$. appendiculatum (CGI) e $M$. sinense (SF 53) pelo trato gastrintestinal de bovinos e observou a presença de conídios após 14 dias de incubação. No estudo, a observação mais precoce do isolado pode indicar melhor adaptação após a passagem através do trato gastrintestinal. Assis e Araújo (2003) observaram o isolamento do $M$. sinense (SF 470) e do isolado $M$. appendiculatum (CGI) em eqüinos após 24 horas da administração por VO. Em outro experimento, com os isolados $M$. sinense (SF 470) e M. appendiculatum (CGI) administrados a caprinos, Assis et al. (2004) observaram tempo de isolamento idêntico ao do presente estudo em ambas as espécies estudadas. Melo et al. (2003) encontraram o fungo $M$. thaumasium em placas confeccionadas com fezes de caprinos coletadas $21 \mathrm{~h}$ e $24 \mathrm{~h}$ após a inoculação.

O M. sinense (SF 470) permaneceu viável após a passagem pelo trato gastrintestinal de bovinos sem afetar sua capacidade predatória. Os fungos nematófagos predadores formam armadilhas, a intervalos, ao longo da hifa. As armadilhas constituem a resposta do fungo à presença de nematóides ou de substâncias derivadas destes ou, ainda, a vários outros compostos de origem biológica. A diferenciação da hifa ocorre dentro de $24 \mathrm{~h}$, geralmente entre três e seis horas após o contato do nematóide com o fungo, e numerosas estruturas de captura podem ser produzidas. Foram observadas larvas infectantes de Cooperia spp e Haemonchus spp em armadilhas do isolado $M$. sinense nas placas de Petri referentes a todos os tempos avaliados.

Araújo et al. (1999) demonstraram a eficácia de um isolado de $M$. thaumasium em passar pelo trato gastrintestinal de bovinos, preservando a capacidade de predar L3 de $H$. placei. Em ensaios in vitro, Araújo et al. (2000b) testaram péletes do mesmo isolado em diferentes temperaturas e sal mineral. Os péletes de $M$. thaumasium permaneceram viáveis por 16 semanas à temperatura de $4^{\circ} \mathrm{C}$ e em sal mineral. Alves et al. (2003) testaram péletes do isolado de $M$. thaumasium no controle das nematodioses gastrintestinais de bovinos a campo e observaram, em seis meses de experimento, redução de $88,8 \%$ no número de ovos por grama de fezes dos animais tratados em relação ao grupo-controle.

O número de larvas infectantes de nematóides gastrintestinais de bovinos recuperadas dos animais do grupo-controle foi maior $(\mathrm{P}<0,05)$ do que o do grupo tratado (Tab. 1). Essa diferença aumentou durante o experimento, com $69,9 \%$ de redução nos animais tratados em relação aos não tratados na colheita de $96 \mathrm{~h}$.

Tabela 1. Número médio e desvio-padrão e porcentagem de redução de larvas infectantes de nematóides gastrintestinais de bovinos recuperadas das placas de Petri, segundo o tempo após o tratamento com o fungo predador Monacrosporium sinense (SF 470) e o grupo

\begin{tabular}{lccc}
\hline Tempo & Tratado & Controle & Redução (\%) \\
\hline 12 & $2263 \pm 2,53$ & $3804 \pm 1,31$ & 40,51 \\
18 & $2013 \pm 1,76$ & $3775 \pm 1,18$ & 46,67 \\
24 & $1909 \pm 1,48$ & $3630 \pm 2,04$ & 52,58 \\
48 & $1794 \pm 1,92$ & $3030 \pm 2,67$ & 59,20 \\
72 & $1486 \pm 2,06$ & $3842 \pm 1,82$ & 61,32 \\
96 & $1171 \pm 1,59$ & $3887 \pm 2,46$ & 69,87 \\
\hline
\end{tabular}

Na coprocultura, o número de larvas infectantes de Cooperia spp e Haemonchus spp recuperadas de bezerros do grupo-controle, no exame das 
amostras de fezes $(20 \mathrm{~g})$ foi maior $(\mathrm{P}<0,05)$ do que o de larvas do grupo tratado (Tab. 2). Não se observou redução na coprocultura das amostras colhidas $12 \mathrm{~h}$ pós-tratamento; no final das observações (96h), a redução foi de 61,3\%.

Os valores médios obtidos da participação percentual das larvas infectantes de Cooperia spp e Haemonchus spp nas placas e nas coproculturas dos animais dos grupos tratado e controle encontram-se nas Tab. 3 e 4, respectivamente.
Tabela 2. Média e desvio-padrão e percentual de redução de larvas infectantes de nematóides gastrintestinais de bovinos recuperadas das coproculturas, segundo o tempo após o tratamento com o fungo predador Monacrosporium sinense (SF 470) e o grupo

\begin{tabular}{lccc}
\hline Tempo & Tratado & Controle & Redução (\%) \\
\hline 12 & $16361 \pm 2,37$ & $15835 \pm 2,16$ & - \\
18 & $10403 \pm 1,73$ & $15475 \pm 1,35$ & 32,77 \\
24 & $8845 \pm 1,36$ & $16738 \pm 1,47$ & 47,15 \\
48 & $7864 \pm 2,51$ & $16231 \pm 1,97$ & 51,54 \\
72 & $6529 \pm 1,69$ & $15855 \pm 2,08$ & 58,82 \\
96 & $6082 \pm 2,03$ & $15729 \pm 2,63$ & 61,33 \\
\hline
\end{tabular}

Tabela 3. Porcentagem de larvas infectantes de Cooperia spp e Haemonchus spp recuperadas das placas de Petri com fezes de bovinos, segundo o tempo após tratamento com o fungo predador Monacrosporium sinense (SF 470) e o grupo

\begin{tabular}{lccccc}
\hline \multirow{2}{*}{ Tempo } & \multicolumn{2}{c}{ Tratado } & & \multicolumn{2}{c}{ Controle } \\
\cline { 2 - 3 } \cline { 5 - 6 } & Cooperia sp. & Haemonchus $s p$. & & Cooperia sp. & Haemonchus sp. \\
\hline 12 & 62,90 & 37,10 & 34,40 & 64,30 & 35,70 \\
18 & 65,60 & 45,70 & & 64,30 & 35,70 \\
24 & 54,30 & 47,60 & & 57,70 & 42,30 \\
48 & 52,40 & 45,15 & & 63,94 & 47,06 \\
72 & 53,85 & 37,00 & & 68,75 & 36,30 \\
96 & 63,00 & &
\end{tabular}

Tabela 4. Porcentagem de larvas infectantes de Cooperia sp. e Haemonchus sp. recuperadas das coproculturas de bovinos, segundo o tempo após o tratamento com o fungo predador Monacrosporium sinense (SF 470) e o grupo

\begin{tabular}{lccccc}
\hline \multirow{2}{*}{ Tempo } & \multicolumn{2}{c}{ Tratado } & & \multicolumn{2}{c}{ Controle } \\
\cline { 2 - 3 } \cline { 5 - 6 } & Cooperia sp. & Haemonchus sp. & & Cooperia sp. & Haemonchus sp. \\
\hline 12 & 74 & 26 & & 63 & 37 \\
18 & 71 & 29 & & 72 & 28 \\
24 & 66 & 34 & & 76 & 24 \\
48 & 56 & 22 & & 51 & 49 \\
72 & 78 & 29 & & 56 & 44 \\
96 & 71 & & 87 & 13 \\
\hline
\end{tabular}

Nas fezes dos animais de ambos os grupos houve maior ocorrência de Cooperia spp do que de Haemonchus spp.

O coeficiente de correlação linear entre as médias do número de larvas de nematóides infectantes recuperadas dos animais tratados e não tratados foi $\mathrm{r}=-0,68$. $\mathrm{O}$ valor negativo indica que o fungo $M$. sinense (isolado SF 470) matém a capacidade predatória após a passagem pelo trato gastrintestinal de bovinos, expressa pelo número de larvas infectantes recuperadas das fezes até $96 \mathrm{~h}$ depois da administração de péletes fúngicos.

\section{CONCLUSÃO}

Péletes do fungo nematófago Monacrosporium sinense mostraram-se promissores no controle das nematodioses gastrintestinais de bovinos, em condições de laboratório.

\section{REFERÊNCIAS BIBLIOGRÁFICAS}

ALVES, P.H.; ARAÚJO, J.V.; GUIMARÃES, M.P. et al. Aplicação de formulação do fungo predador de nematóides Monacrosporium thaumasium no controle de nematóides de bovinos. Arq. Bras. Med. Vet. Zootec., v.55, p.568-573, 2003. 
ARAÚJO, J.V. Interação entre larvas infectantes de Cooperia punctata e fungos predadores do gênero Arthrobotrys, caracterização de isolados de Arthrobotrys e seu uso no controle biológico de nematódeos parasitos gastrintestinais de bovinos. 1996. 110f. Tese (Doutorado em Parasitologia) - Instituto de Ciências Biológicas, Universidade Federal de Minas Gerais, Belo Horizonte, MG.

ARAÚJO, J.V.; GOMES, A.P.S.; GUIMARÃES, M.P. Biological control of bovine gastrointestinal nematode parasites in southeastern Brazil by the nematode-trapping fungus Arthrobotrys robusta. Rev. Bras. Parasitol., v.7, p.117-122, 1998.

ARAÚJO, J.V.; NETO, A.P.; AZEVEDO, M.H.F. Screening parasitic nematode-trapping fungi Arthrobotrys for passage through the gastrointestinal tract of calves. Arq. Bras. Med. Vet. Zootec., v.48, p.543-552, 1996.

ARAÚJO, J.V.; SAMPAIO, W.M.; VASCONCELLOS, R.S. et al. Effects of different temperatures and mineral salt on "pellets" of Monacrosporium thaumasium - a nematode-trapping fungus. Vet. Arhiv., v.70, p.181-190, $2000 \mathrm{~b}$.

ARAÚJO, J.V.; SANTOS, M.A.; FERRAZ, S. et al. Controle de larvas infectantes de Haemonchus placei por fungos predadores da espécie Monacrosporium ellypsosporum em condições de laboratório. Arq. Bras. Med. Vet. Zootec., v.44, p.521-526, 1992.

ARAÚJO, J.V.; STEPHANO, M.A.; SAMPAIO, W.M. Effects of temperature, mineral salt and passage through the gastrointestinal tract of calves on sodium alginate formulation of Arthrobotrys robusta. Rev. Bras. Parasitol. Vet., v.9, p.55-60, 2000a.

ARAÚJO, J.V.; STEPHANO, M.A.; SAMPAIO, W.M. Passage of nematode trapping fungi through the gastrointestinal tract of calves. Vet. Arhiv., v.2, p.69-78, 1999.

ASSIS, R.C.L.; ARAÚJO, J.V. Avaliação da viabilidade de fungos predadores do gênero Monacrosporium em predar ciatostomíneos após a passagem pelo trato gastrintestinal de equinos em formulação de alginato de sódio. Rev. Bras. Parasitol. Vet., v.12, p.109-113, 2003.

ASSIS, R.C.L.; ARAÚJO, J.V.; GANDRA, J.R. et al. Avaliação do fungos predadores do gênero Monacrosporium sobre larvas infectantes de Haemonchus contortus de caprinos. Rev. Bras. Cienc. Vet., v.11, 2004 (No prelo).

CAMPOS, A.K. Efeito da criopreservação e de formulações sobre a viabilidade do fungo nematófago Monacrosporium spp. 2002. 48f. Dissertação (Mestrado em Medicina Veterinária) - Departamento de Veterinária, Universidade Federal de Viçosa, Viçosa, MG.

CASTRO, A.C. Avaliação de fungos Deuteromycetes sobre as fases pré-parasíticas de Cyathostominae
(Nematoda-Strongylidae). 2000. 100f. Dissertação (Mestrado em Parasitologia Veterinária)- Departamento de Parasitologia Animal, Universidade Federal Rural do Rio de Janeiro, Seropédica, RJ.

DUDDINGTON, C.L. Notes on the technique of handling predaceous fungi. Trans. Brit. Mycol. Soc., v.38, p.97$103,1955$.

GOMES, A.S.; ARAÚJO, J.V.; RIBEIRO, R.C.F. Differential in vitro pathogenicity of predatory fungi of the genus Monacrosporium for phytonematodes, freeliving nematodes and parasitic nematodes of cattle. Braz. J. Med. Biol. Res., v. 32, p. 79-83, 1999.

GORDON, H.M.; WHITLOCK, H.V. A new technique for counting nematode eggs in sheep faeces. J. Counc. S. Ind. Res., v.12, p.50-52, 1939.

KEITH, R.K. The differentiation on the infective larvae of some common nematode parasites of cattle. Aust. J. Zool., v.1, p.223-235, 1953.

LACKEY, B.A.; MULDOON, A.E.; JAFFE, B.A. Alginate pellet formulation of Hirsutella rossiliensis for biological control of plant-parasitic nematodes. Biol. Cont., v.3, p.155-160, 1993.

LIU, X.Z.; ZHANG, K.Q. Nematode-trapping species of Monacrosporium with special reference to two new species. Mycol. Res., v.98, p.862-868, 1994.

MEEUSEN, E. Rational design of nematode vaccinesnatural antigens. Int. J. Parasitol., v.26, p.813-818, 1996.

MELO, L.M.; BEVILÁQUA, C. M. L.; ARAÚJO, J.V. et al. Passagem do fungo Monacrosporium thaumasium através do trato gastrointestinal de caprinos e atividade predatória contra Haemonchus contortus. Ciênc. Rural, v.33, p.169-171, 2003.

RIBEIRO, R.R. Seleção de fungos predadores do gênero Monacrosporium para passagem através do trato gastrintestinal de bezerros. 2002. 53f. Dissertação (Mestrado em Medicina Veterinária) - Departamento de Veterinária, Universidade Federal de Viçosa, Viçosa, MG.

SANTOS, M.A.; FERRAZ, S.; MUCHOVEJ, J. Detection and ecology of nematophagous fungi from Brazilian soils. Nematol. Bras., v.15, p.121-134, 1991.

WALKER, H.L.; CONNICK, W.J. Sodium alginate for production and formulation of mycoherbicides. Weed Sci., v.31, p.333-338, 1983.

WALLER, P.J.; LARSEN, M. The role of nematophagous fungi in the biological control of nematode parasites of livestock. Int. J. Parasitol., v.23, p.539-546, 1993.

WOOLASTON, R.R.; BAKER, R.L. Prospects of breeding for parasite resistance. Int. J. Parasitol., v.26, p.845-855, 1996. 